Pak. j. sci. ind. res. Ser. A: phys. sci. 201457 (1) 53-58

\title{
Investigation of Soil Fertility at a Remote Site in Karachi, Pakistan
}

\author{
Khaula Shirin*, Sheraz Shafiq, Saima Imad, Sofia Khalique Alvi and Mahroze Ahmed Khan \\ Applied Chemistry Research Centre, PCSIR Laboratories Complex Karachi, \\ Shahrah-e-Dr.Salimuzzaman Siddiqui, Karachi-75280, Pakistan
}

(received January 31, 2012; revised July 25, 2012; accepted September 25, 2012)

\begin{abstract}
This study reveals chemical and physical properties of soils collected from a remote site at Karachi, Pakistan. Altogether 23 parameters were determined. Out of 12 soil samples 11 were categorised as sand or sandy loams, $\mathrm{pH}$ varied between $7.35-8.49$, density ranged between $1.61-2.39 \mathrm{gm} / \mathrm{cm}^{3}$, the conductivity of 1:2 water extracts varied up to a great extent i.e., between $0.437-16.47 \mathrm{mS} / \mathrm{m}^{3}$. Sodium (Na) contents were higher in ammonium acetate extract when compared with 1:2 water extract. The bicarbonate $\left(\mathrm{HCO}_{3}\right)$ contents were ranged between $0.17-1.73 \mathrm{ppm}$. The organic matter contents were low (0.81-2.21\%); these soils were also deficient in their macronutrient contents. Specifically, the ranges of nitrogen $(\mathrm{N})$, phosphorous $(\mathrm{P})$, potassium $(\mathrm{K})$, calcium $(\mathrm{Ca})$, magnesium $(\mathrm{Mg})$ and sulphur $(\mathrm{S})$ were 0.04-1.16\%, 0.25-15.99 ppm, 4.40-135.89 ppm, 0.001-0.199\%, 0.001-0.019\% and 0.01-0.143\%, respectively. Heavy metals were determined in diethylene-triamine-pentaacetic acid (DTPA) extracts and the levels of iron (Fe), copper $(\mathrm{Cu})$, manganese $(\mathrm{Mn})$, and zinc $(\mathrm{Zn})$ in these samples were 1.86-32.80 ppm, 1.68-7.69 ppm, 16.51-75.28 and 0.25-20.75 ppm, respectively. Toxic heavy metals, lead $(\mathrm{Pb})$ and nickel $(\mathrm{Ni})$ contents were also estimated and their concentration was found low ranging between 0.91-5.63 ppm and 0.32-1.26 ppm, respectively.
\end{abstract}

Keywords: macronutrients, micronutrients, organic matter, soil fertility, soil texture, toxic metals

\section{Introduction}

Soil is the natural medium for the growth of plants. It provides support to the plants and also supplies essential nutrients and water. Soil is composed of four major components, the mineral matter is the most abundant component which comprises almost $45 \%$ volume of soil, organic matter occupies almost $5 \%$ volume, while, the remaining $50 \%$ of total pore space of the soil is occupied by water and air in a 1:1 ratio (Gupta, 2004). The mineral matter consists of stones, gravels, silt and clays and it also defines the structure of the soil. The organic matter of soil comprises of plant, animal and microbial residues, it gives colour to the soil, helps water retention, cementing action, buffering action, mineralisation and also affects the persistence and biodegradability of other organic compounds such as pesticides; hence, soil organic matter modifies and controls their rate of application (Schnitzer and Khan, 1978). The soil air has a relatively high concentration of carbon dioxide (0.25-3\%) as compared to carbon dioxide levels in atmospheric air $(0.03 \%)$, whereas, the oxygen levels are generally lower $(<20 \%)$, however, the levels of nitrogen are almost the same (79.2\%), in soil air as compared to atmospheric air (Tan, 2011).

The capacity of soil to provide essential nutrients for plant growth is called its fertility, which is necessary for *Authour for correspondence; E-mail:khaula_ark@yahoo.com productive soil, however, a fertile soil may not be a productive because there are other parameters which affect soil productivity. Essential elements for plant growth and completion of life cycle are classified into basic macro- and micronutrients. For example, carbon, hydrogen, and oxygen constitute $96 \%$ of total dry plant matter and are the basic nutrient required for plant development. In addition, these elements are abundantly present in the atmosphere and therefore, do not need to be physically applied to soils for plant development.

Macronutrients which are required in large quantity for plant growth include nitrogen $(\mathrm{N})$, phosphorous $(\mathrm{P})$, potassium $(\mathrm{K})$, calcium $(\mathrm{Ca})$, magnesium $(\mathrm{Mg})$ and sulphur (S), in which N, P and $\mathrm{K}$ are major or primary nutrients, whereas, $\mathrm{Ca}, \mathrm{Mg}$ and $\mathrm{S}$ are secondary nutrients. Primary nutrients are often deficient in soils and hence, applied as fertilisers. Micronutrients are essential for optimum plant growth in minute quantities, however, their excess concentrations may lead to harmful effects to the plant. Important micronutrients include iron $(\mathrm{Fe})$, zinc $(\mathrm{Zn})$, copper $(\mathrm{Cu})$, manganese $(\mathrm{Mn})$, boron $(\mathrm{B})$, molybdenum (Mo) and chloride (Cl).

There are several factors that influence the release and availability of nutrients. These factors include soil $\mathrm{pH}$, temperature, moisture, aeration, application of fertilisers such as manure and microorganism activity 
(Comerford, 2005). As nutrients are absorbed by the plant, nutrient concentrations become depleted in the soil layers near plant roots and are replenished by the mobility of nutrients through the soil medium. Most nutrients are present in soil in three forms: (1) unavailable nutrients that cannot be absorbed directly by the plant which need to be fixed into intermediate nutrients by microorganisms, (2) intermediate nutrients that act as long-term reservoirs that are in equilibrium with unavailable nutrients and (3) labile nutrients that are loosely held by the soil and readily available to soil solutions in the form of available nutrients. Equilibrium can be established between the intermediate and the labile nutrients over a short period of time. Deficiencies of nutrients can lead to the reduction of plant size, discolouration of leaves, slow growth, weak stalk, shrivelled fruits and seeds and the wilting of leaves among other negative consequences (Gerloff, 1987).

The reduction of soil productivity is referred to as soil degradation. There are many problems associated with soil degradation such as soil erosion, loss of fertility, salinity, alkalinity, acidity and water logging. Flooding and droughts can also contribute toward soil degradation. Soil testing practices are quite important for proper characterisation of soil and its fertility. The site of the study located at a remote site in Karachi, Pakistan was once known for its beautiful gardens, but during past 10 years the quality of this soil has been degraded up to a great extent. Apparently salinity and water logging are the main causes for this degradation, therefore, this detailed study was planned to determine the level of degradation and determination of its fertility. The results of the study would help the reclamation of the site and make it fertile once again.

\section{Materials and Methods}

Reagents and equipments. All chemicals used for the experiments were of AR grade, double distilled water was used for the preparation of reagents and samples. The equipments used during the course of this study were, Hitachi Z 5000 atomic absorption spectrophotometer equipped with Zeeman background correction, Jenway PFP 7 flame photometer, Jenway ion meter and Thermo Nicol UV-vis spectrophotometer. All equipments were used as per manufacturers' instructions and recommendations.

Methodology. Standard methods for the testing of soil were used to estimate various physical and chemical parameters. $\mathrm{pH}$, conductivity, $\mathrm{Na}, \mathrm{K}, \mathrm{HCO}_{3}{ }^{-}, \mathrm{S}$ and $\mathrm{Cl}^{-}$ were determined in 1:2 soil water extract. Na content was also determined in ammonium acetate extract. $\mathrm{HCO}_{3}{ }^{-}$ were estimated with $\mathrm{HCl}$ titration, $\mathrm{Na}$ and $\mathrm{K}$ were estimated on flame photometer. $\mathrm{Ca}$ and $\mathrm{Mg}$ were determined with ethylene-diaminetetraacetic acid (EDTA) complexometric titration, while, $\mathrm{Cl}^{-}$was estimated by argentometric titration. $\mathrm{S}$ was estimated gravimetrically as $\mathrm{BaSO}_{4}$. Soil texture was determined using hygrometer. Bulk and particle density was determined through pycnometer. Total organic carbon and organic matter were determined by Walky and Black rapid titration method, $\mathrm{P}$ was estimated spectrophotometrically using Murphy Riley solution, while, $\mathrm{N}$ contents were determined by Kjeldhal distillation method. Trace metals (Fe, Cu, $\mathrm{Pb}, \mathrm{Mn}, \mathrm{Ni}$, and $\mathrm{Zn}$ ) were estimated in diethylenetriaminepentaacetic acid (DTPA) extract on atomic absorption spectrophotometer (Gupta, 2004).

Site of the study. This study was conducted at PCSIR Laboratories Complex Karachi, Pakistan and its suburbs, which is located at a remote area of Karachi (24 $57^{\circ}$ $45^{\prime \prime} \mathrm{N}, 67^{\circ} 7^{\prime} 30^{\prime \prime} \mathrm{E}$ ). The area of the study is around $2 \mathrm{~km}^{2}$. More than $60 \%$ of the area is lying vacant with wild vegetation. A residential colony, the Laboratory and PSTC Training Center are included in the study area. There are two fields in the vicinity which are utilised for field experiments on different crops like sunflower, corn, sugarcane etc., and some ornamental plants like roses, tube roses etc. There are 5 gardens at different locations and a graveyard is also included in the campus. The vacant land is acquired by wild shrubs which grow quickly.

Sample collection. The samples were collected from 12 different locations to cover almost all the campus area using standard protocol for the soil sampling. To estimate the soil quality at vegetation and non vegetation sites, the samples were selected, where there was some vegetation like gardens, fields etc., and in order to compare their quality some barren soils were also selected. Locations 1, 2, 6, 7, 11 were barren or covered with wild vegetation, whereas, location $3,4,5,8,12$ were gardens and location $\mathbf{9}$ and $\mathbf{1 0}$ were the fields utilised for experimental crops. These locations are given in Fig. 1. The surface litter was scraped away then the soil surface was ploughed up to a depth of about $12 \mathrm{~cm}$ from 5 different spots at the location, and individual samples were then mixed together to make a composite sample. The representative sample was obtained by further quartering of composite sample to obtain approximately $500 \mathrm{~g}$ of soil (Iqbal et al., 2001). 


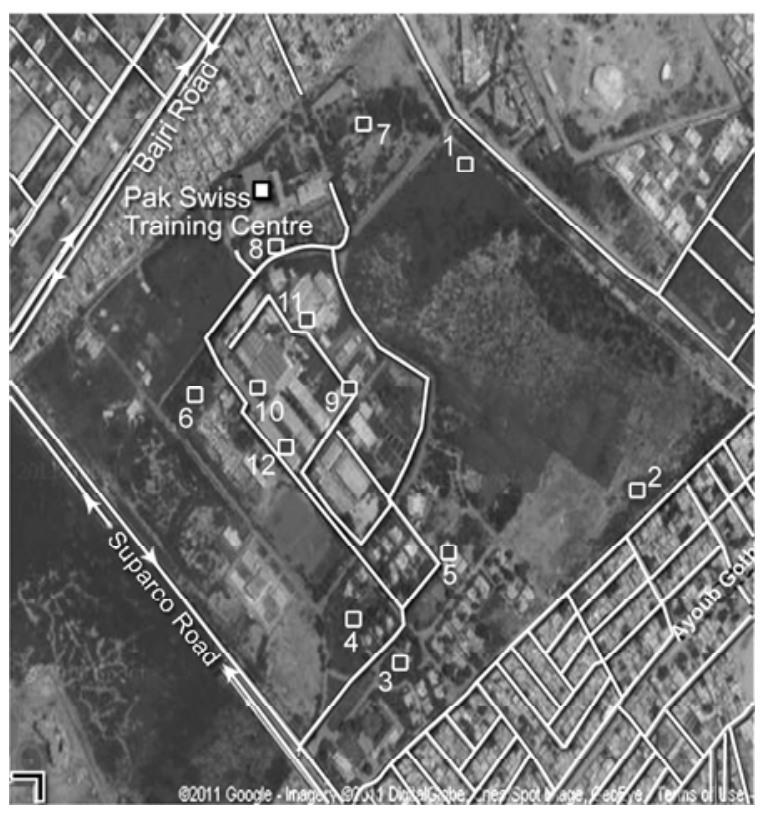

Fig. 1. Sample locations.

\section{Results and Discussion}

Physical testing of soil. The physical parameters i.e., soil texture, $\mathrm{pH}$, density, conductivity and total dissolved soolids (TDS) are described in Table 1. Most of the samples collected from the study area lie in the category of sand or sandy loams (Table 1). Sandy soils can lose plant nutrients and water rapidly and hence affect soil fertility. Such soils are not considered perfect medium for the cultivation of crop plants (Oades and Waters, 1991).

The $\mathrm{pH}$ of the collected samples was slightly alkaline ranging from 7.35-8.49 which may be due to the low rainfall in the area. The rainwater contains dissolved carbon dioxide in the form of carbonic acids which leach away the basic cations like calcium, magnesium, potassium and sodium and replace it with $\mathrm{H}^{+}$. The nutrient uptake of alkaline soils is also lower as compared to the acidic soils, however, this problem could be rectified by adding water soluble chelates onto the soil.

The soil density ranged between 1.590-2.395 g/cm which is typical for normal soils (Tanji, 1990). The conductivity of $1: 2$ soil water extract varied in a significant range with the lowest value at the sampling point $1\left(0.437 \mathrm{mS} / \mathrm{m}^{3}\right)$ and as high as $16.47 \mathrm{mS} / \mathrm{m}^{3}$ at sampling point 10. Conductivity plays an important role in soil fertility. Low conductivity (i.e., $<0.8 \mathrm{mS} / \mathrm{m}^{3}$ ) impose no deleterious effects on the crop, however, when conductivity is less than $0.2 \mathrm{mS} / \mathrm{m}^{3}$, the soil is deficient in $\mathrm{N}$ and $\mathrm{K}$, while, a range of conductivity between $0.8-1.6 \mathrm{mS} / \mathrm{m}^{3}$ is critical for salt sensitive crops. A range of conductivity between $1.6-2.5 \mathrm{mS} / \mathrm{m}^{3}$ may be critical even for salt tolerant crops, while, conductivity exceeding $2.5 \mathrm{mS} / \mathrm{m}^{3}$ would be injurious for most crops (Wolf, 1999). Our study result showed that 8 sampling locations out of $\mathbf{1 2}$ are not suitable for cultivation and it seemed the reason behind low yield during field experiments on different crops like sunflower, sugarcane and high maintenance cost of the gardens.

Chemical composition of the soil. Sodium contents were determined both in 1:2 water extract and ammonium acetate extract and are given in Table 2. The contents were high in ammonium acetate extract as compared to the water extract. The concentration of $\mathrm{Na}$ in 1:2 water extract was very strongly correlated with the $\mathrm{Cl}$

Table 1. Physical testing of studied soils

\begin{tabular}{|c|c|c|c|c|c|c|c|c|}
\hline \multirow[t]{2}{*}{ Sample } & \multicolumn{4}{|c|}{ Soil texture } & \multirow{2}{*}{$\begin{array}{l}\mathrm{pH} \\
\text { (1:2 water extract) }\end{array}$} & \multirow{2}{*}{$\begin{array}{l}\text { Bulk density } \\
\left(\mathrm{g} / \mathrm{cm}^{3}\right)\end{array}$} & \multirow{2}{*}{$\begin{array}{l}\text { Conductivity } \\
(\mathrm{mS} / \mathrm{cm})\end{array}$} & \multirow{2}{*}{$\begin{array}{l}\text { TDS } \\
(\mathrm{ppm})\end{array}$} \\
\hline & Sand \% & Clay \% & Silt \% & Texture & & & & \\
\hline 1 & 88.70 & 6.78 & 4.52 & Sand & 7.35 & 1.915 & 12.74 & 7640 \\
\hline 2 & 63.84 & 11.30 & 24.86 & Sandy loam & 7.42 & 1.959 & 7.3 & 4760 \\
\hline 3 & 79.66 & 2.26 & 18.08 & Sand & 7.60 & 2.395 & 2.39 & 1440 \\
\hline 4 & 68.36 & 11.30 & 20.34 & Sandy loam & 8.09 & 1.827 & 2.70 & 1620 \\
\hline 5 & 57.06 & 20.34 & 22.6 & Sandy loam & 7.87 & 1.701 & 1.523 & 910 \\
\hline 6 & 70.62 & 9.04 & 20.34 & Sand & 7.88 & 1.733 & 2.75 & 1650 \\
\hline 7 & 77.40 & 6.78 & 15.82 & Sand & 7.58 & 1.719 & 1.861 & 1120 \\
\hline 8 & 63.84 & 11.3 & 24.86 & Sandy loam & 7.52 & 1.590 & 5.59 & 2760 \\
\hline 9 & 72.88 & 11.3 & 15.82 & Sandy loam & 7.63 & 1.613 & 8.89 & 5330 \\
\hline 10 & 61.58 & 13.56 & 24.86 & Sandy loam & 7.92 & 1.757 & 16.47 & 9880 \\
\hline 11 & 54.80 & 40.68 & 4.52 & Clay loam & 8.25 & 2.059 & 4.46 & 2670 \\
\hline 12 & 63.84 & 11.30 & 24.86 & Sandy loam & 8.49 & 1.759 & 0.437 & 260 \\
\hline
\end{tabular}


concentration; $\left(\mathrm{R}^{2}=0.697, \mathrm{P}>0.001\right), \mathrm{Cl}^{-}$contents were varied between $0.01-0.66 \%$. The soil samples can be characterised as highly saline. The $\mathrm{HCO}_{3}{ }^{-}$contents were low, varying within the range between $0.23-1.73 \mathrm{ppm}$.

Table 2. Major cations and anions in studied soils

\begin{tabular}{|c|c|c|c|c|}
\hline \multirow[t]{2}{*}{ Sample } & \multicolumn{3}{|c|}{ 1:2 Water extract } & \multirow{2}{*}{$\begin{array}{l}\text { Sodium (\%) } \\
\text { in ammonium } \\
\text { acetate extract }\end{array}$} \\
\hline & $\begin{array}{l}\text { Sodium } \\
\text { (\%) }\end{array}$ & $\begin{array}{l}\text { Bicarbonate } \\
\text { (ppm) }\end{array}$ & $\begin{array}{l}\text { Chloride } \\
\text { (\%) }\end{array}$ & \\
\hline 1 & 0.12 & 0.50 & 0.53 & 0.14 \\
\hline 2 & 0.04 & 0.43 & 0.32 & 0.12 \\
\hline 3 & 0.03 & 0.67 & 0.06 & 0.04 \\
\hline 4 & 0.06 & 0.23 & 0.06 & 0.08 \\
\hline 5 & 0.02 & 1.23 & 0.04 & 0.04 \\
\hline 6 & 0.06 & 0.50 & 0.08 & 0.14 \\
\hline 7 & 0.01 & 0.63 & 0.05 & 0.06 \\
\hline 8 & 0.06 & 0.28 & 0.35 & 0.07 \\
\hline 9 & 0.15 & 0.26 & 0.34 & 0.21 \\
\hline 10 & 0.33 & 0.17 & 0.66 & 0.41 \\
\hline 11 & 0.06 & 0.85 & 0.14 & 0.09 \\
\hline 12 & 0.004 & 1.73 & 0.01 & 0.01 \\
\hline
\end{tabular}

Organic matter. Organic matter in the soil consists of plants, animal and microbial residues at various stages of decay. It mainly contains $5 \%$ of total nitrogen, therefore, it serves as the resource for nitrogen (Beare et al., 1994). The organic matter (OM) decomposes to release the nutrient. The collected samples of soil contain $0.81-2.21 \%$ organic matter, while the total organic carbon (TOC) ranged from 0.60 to $1.27 \%$. When organic matter content is correlated with the soil texture, it can be inferred that the organic matter contents are comparatively higher with increasing clay content of the soil (Greenland, 1965). The results of organic matter concentration are given Table 3.

Table 3. Organic matter and organic carbon in studied soils

\begin{tabular}{lll}
\hline \hline Sample & $\begin{array}{l}\text { Organic matter } \\
\text { (OM, \%) }\end{array}$ & $\begin{array}{l}\text { Total organic carbon } \\
\text { (TOC, \%) }\end{array}$ \\
\hline 1 & 1.20 & 0.69 \\
2 & 1.08 & 0.81 \\
3 & 0.81 & 0.46 \\
4 & 1.04 & 0.60 \\
5 & 1.43 & 0.82 \\
6 & 1.13 & 0.65 \\
7 & 1.34 & 0.77 \\
8 & 2.21 & 1.27 \\
9 & 1.31 & 0.75 \\
10 & 1.72 & 0.99 \\
11 & 1.22 & 0.70 \\
12 & 1.47 & 0.84 \\
\hline \hline
\end{tabular}

Macronutrients. During the course of this study, macronutrients (N, P, K, Ca, Mg, and S) were also estimated (Table 4). It has been observed that soil is deficient of primary and secondary macronutrients. The $\mathrm{N}$ contents of the collected samples for this study ranged between $0.05-1.16 \%$, this indicates that the studied soil is nitrogen deficient. According to the literature N-deficiency produces small plants with light green or light yellow leaves, the chlorosis produces at the leaf tip and then the leaf either dries or drops down (Stevenson and Cole, 1999). In the present study, P concentration of soil varied between $0.25-15.99$, while, $K$ content between 4.40-135.89 ppm in 1:2 water extract. These ranges lie below the normal range for sandy soils (Gupta, 2004). Due to the deficiency of $\mathrm{P}$ there is limited root development which results in delayed maturity and hence affects fruit development. Similarly K deficient plants have also restricted growth and discolouration of leaves (Egilla et al., 2001; Stevenson and Cole, 1999).

Secondary macronutrients such as $\mathrm{Ca}(0.005-0.199 \%)$, $\mathrm{Mg}(0.001-0.019 \%)$ and S (0.01-0.143) were found in low concentration when compared with the normal range of these macronutrients in sandy soils (Troeh and Thompsom, 2005). Ca and S deficiency in the soils affects the root growth, whereas, Ca if not supplied to the plant in sufficient quantity, would result in late emergence of fruits. The Mg and S deficiency affects the colour of the leaves (Marschner et al., 1996).

Heavy metals. Heavy metals can be characterised as micronutrients which are essential for optimum growth of plants and toxic substances which affect the crop quality. Certain micronutrients if present in high concentration may also act as toxic substances. United States Environmental Protection Agency (USEPA) has set limits for residential and industrial soil for inorganic pollutants. The concentration limitations for $\mathrm{Pb}, \mathrm{Cu}, \mathrm{Ni}$ and Mn concentration in soil are 400, 3100, 1600 and $1800 \mathrm{mg} / \mathrm{kg}$, respectively, (USEPA, 1996). There is no limit for concentration of Fe and Zinc.

$\mathrm{Fe}, \mathrm{Cu}, \mathrm{Mn}$ and $\mathrm{Zn}$ are characterised as micronutrients. The levels of these metals in DTPA extracts in collected soil samples were 1.86-32.8 ppm for Fe, $1.68-7.69 \mathrm{ppm}$ for $\mathrm{Cu}, 16.51-75.3 \mathrm{ppm}$ for $\mathrm{Mn}$, and $0.25-20.75 \mathrm{ppm}$ for $\mathrm{Zn}$. The results given in Table 5 indicate that all the micronutrients are present in sufficient quantity (Yu and Rengel, 1999). Toxic heavy metals like $\mathrm{Pb}$ and $\mathrm{Ni}$ were also estimated in these samples and results are also given in Table $5 . \mathrm{Pb}$ is supposed to be a considerably 
Table 4. Macronutrients at studied soils

\begin{tabular}{lllllll}
\hline \hline Sample & $\mathrm{N}(\%)$ & $\mathrm{P}(\mathrm{ppm})$ & $\mathrm{K}(\mathrm{ppm})$ & $\mathrm{Ca}(\%)$ & $\mathrm{Mg}(\%)$ & $\mathrm{S}(\%)$ \\
\hline 1 & 0.094 & 7.66 & 24.88 & 0.199 & 0.010 & 0.07 \\
2 & 0.30 & 0.25 & 17.22 & 0.081 & 0.014 & 0.013 \\
3 & 0.46 & 6.19 & 135.89 & 0.01 & 0.003 & 0.01 \\
4 & 0.72 & 15.99 & 89.53 & 0.007 & 0.004 & 0.02 \\
5 & 0.05 & 2.04 & 18.49 & 0.02 & 0.002 & 0.023 \\
6 & 0.04 & 4.05 & 17.31 & 0.005 & 0.008 & 0.023 \\
7 & 0.33 & 1.82 & 4.40 & 0.013 & 0.005 & 0.007 \\
8 & 0.25 & 7.99 & 102.67 & 0.045 & 0.003 & 0.02 \\
9 & BDL* & 2.03 & 24.76 & 0.051 & 0.011 & 0.023 \\
10 & 0.64 & 10.80 & 78.73 & 0.109 & 0.019 & 0.143 \\
11 & 0.48 & 2.06 & 68.73 & 0.003 & 0.003 & 0.023 \\
12 & 1.16 & 12.77 & 58.80 & 0.001 & 0.001 & BDL* \\
\hline \hline
\end{tabular}

*BDL=below detection limit (for nitrogen $0.02 \%$, for sulphur is $0.005 \%$ ).

Table 5. Heavy metals in studied soils

\begin{tabular}{|c|c|c|c|c|c|c|}
\hline \multirow{2}{*}{ Sample } & \multicolumn{4}{|c|}{ Micronutrients } & \multicolumn{2}{|c|}{ Toxic metals } \\
\hline & Fe (ppm) & $\mathrm{Cu}(\mathrm{ppm})$ & Mn (ppm) & $\mathrm{Zn}(\mathrm{ppm})$ & $\mathrm{Pb}(\mathrm{ppm})$ & $\mathrm{Ni}(\mathrm{ppm})$ \\
\hline 1 & 1.86 & 2.34 & 28.97 & 2.8 & 3.22 & 0.46 \\
\hline 2 & 2.56 & 2.23 & 16.51 & 0.25 & 0.91 & 0.35 \\
\hline 3 & 5.90 & 7.69 & 27.74 & 1.78 & 1.39 & 0.32 \\
\hline 4 & 5.98 & 5.02 & 34.86 & 3.78 & 2.03 & 0.52 \\
\hline 5 & 11.18 & 3.49 & 62.13 & 1.38 & 1.95 & 0.83 \\
\hline 6 & 15.27 & 2.26 & 55.54 & 0.44 & 2.46 & 0.73 \\
\hline 7 & 19.88 & 3.87 & 75.28 & 2.01 & 3.13 & 0.86 \\
\hline 8 & 32.80 & 6.07 & 29.64 & 20.75 & 5.63 & 1.26 \\
\hline 9 & 4.49 & 1.68 & 30.83 & 0.64 & 0.92 & 0.48 \\
\hline 10 & 7.74 & 3.11 & 43.88 & 1.99 & 2.85 & 0.52 \\
\hline 11 & 7.68 & 1.87 & 44.19 & 0.31 & 1.22 & 0.53 \\
\hline 12 & 7.36 & 1.87 & 64.44 & 0.33 & 1.91 & 0.72 \\
\hline
\end{tabular}

important toxic heavy metal however, Pb content was not very high in the soil samples and it ranged between 0.91-5.63 ppm, whereas, Ni contents also varied between 0.32-1.26 ppm. The highest metallic content was observed at PSTC site and the field around it, which may be due to the metals molding and smelting which takes place in these areas. The $\mathrm{Ni}$ and $\mathrm{Pb}$ contents in this area are comparable with an effluent irrigated soil from Korangi Industrial Area Karachi, Pakistan, where authors determined almost same range and average of these two metals in the soils (Haq, 2003).

\section{Conclusion}

The area under investigation has serious problems of soil degradation. The soil fertility parameters determined in this study are comparable with recently published data by Kabir et al. (2010). Their findings from another sandy loam textured soil from Karachi are showing that those soils are much better for cultivation as compared to the study area. Their investigated soils were low in TDS, Na and Cl contents, whereas they also have much improved macro and micronutrient contents (Kabir et al., 2010). Present investigation reveals that the soil has apparently lost its productivity. The major problem of the soil is its salinity and high sodium content and the soil can be characterised as sodic soil as the $\mathrm{Na}$ content in ammonium acetate extract is more than $15 \%$ of total extractable cations. The Na content in ammonium acetate extract varies between $0.01-0.41 \%$, while, in water extract it ranges between $0.004-0.33 \%$ which is 
very high and hence these soils can be characterised as saline sodic soils. The reclamation of the saline sodic soils cannot be achieved easily and quickly by simple leaching the excess salt with water and properly draining it out. These soils must be treated with a soil conditioner. The most commonly used soil conditioner for alkaline soils is gypsum. Sulphur replaces most of the Na ions with Ca. The deficiency of micro- and macronutrients may be overcome with the application of suitable fertiliser, which is leachable into the water system.

\section{References}

Beare, M.H., Hendrix, P.F., Coleman, D.C. 1994. Waterstable aggregates and organic matter fractions in conventional and no-tillage soils. Soil Science Society American Journal, 58: 777-786.

Comerford, N.B. 2005. Soil factors affecting nutrient bioavailability. In: Ecological Studies, Nutrient Acquisition by Plants: An Ecological Perspective, H. B. Red (ed.), vol. 181, pp. 1-11, Springer-Verlag, Hiedelberg, Germany.

Egilla, J.N., Davies, F.T., Drew M.C. 2001, Effect of potassium on drought resistance of Hibiscus rosa-sinensis cv. Leprechaun: Plant growth, leaf macro- and micronutrient content and root longevity. Plant and Soil, 229: 213-224.

Gerloff, G.C. 1987. Intact plant screening for tolerance of nutrient deficiency stress. Plant and Soil, 99: 3-16.

Greenland, D.J. 1965. Interactions between clays and organic compounds in soils. Part I. Mechanisms of interaction between clays and defined organic compounds. Soils Fertility, 28: 415-532.

Gupta, P.K. 2004. Methods in Environmental Analysis of Water, Soil and Air, pp. 108, 203, 293, Updesh Purohil for Agrobios (India), Jodhpur, India.

Haq, M.U., Puno, H.K., Saif, M.S. 2003. Contamination of the agricultural land use due to industrial activities in Karachi (Sindh). International Journal of Agriculture and Biology, 5: 150-153.

Cakmak, I., Marschner, H. 1992. Magnesium deficiency and high light intensity enhance activities of superoxide dismutase, ascorbate peroxidase and glutathione reductase in bean leaves. Plant Physiology, 98: 1222-1227.

Iqbal, Y., Alam, S., Khan, M.N., Ishaq, M., Khan, S.A.,
Saleem, M. 2001. Role of micronutrients on agricultural soil and growth of crops. Journal of the Chemical Society of Pakistan, 23: 144-151.

Kabir, M., Iqbal, M.Z., Farooqi, Z.R., Shafiq, M. 2010. Vegetation pattern and soil characteristics of the polluted industrial area of Karachi. Pakistan Journal of Botany, 42: 661-678.

Marschner, H., Kirkby, E.A., Cakmak, I. 1996. Effect of mineral nutritional status on shoot-root partitioning of photoassimilates and cycling of mineral nutrients. Journal of Experimental Botany, 47: 1255-1263.

Oades, J.M., Waters, A.G. 1991. Aggregate hierarchy in soils. Australian Journal of Research, 29: 815-828.

Stevenson, F.A., Cole, M.A. 1999. Cycles of Soil: Carbon, Nitrogen, Phosphorus, Sulfur, Micronutrients, 427 pp., $2^{\text {nd }}$ edition, Jhon Wiley and Sons Ltd., USA.

Schnitzer, M., Khan. 1978. Soil Organic Matter, vol. 8, pp. 137-166, Elsevier Science Publishers, Amsterdam, The Netherlands.

Tan, K.H. 2011. Principles of Soil Chemistry, 41 pp., $4^{\text {th }}$ edition, CRC Press Taylor and Francis, UK.

Tisdall, J.M., Oades, J.M. 1982. Organic matter and water-stable aggregates in soils. Journal of Soil Science, 62: 141-163.

Tanji, K.K. 1990. Agricultural Salinity Assessment and Management, ASCE Manuals \& Reports on Engineering Practice No. 71, American Society of Civil Engineering, New York, USA.

USEPA, 1996. Soil Screening Guidance: Technical Background Document, EPA/540/R-95/128, Office of the Emergency and Ramedial Response, Washington DC., USA.

Wolf, B. 1999. The Fertile Triangle: The Interrelationship of Air, Water, and Nutrients in Maximizing Soil Productivity, 463 pp., Food Product Press, New York, USA.

Yu, Q., Rengel, Z. 1999. Micronutrient deficiency influences plant growth and activities of superoxide dismutases in narrow-leafed lupins. Annals of Botany, 83: 175-182.

Troeh, F.R., Thompson, L.M. 2005. Soil and Soil Fertility, 269 pp., $6^{\text {th }}$ edition, Wiley-Blackwell Publishing, New Jersey, USA. 